\title{
VISÃO BASEADA EM RECURSOS NO CONTEXTO ACADÊMICO: A EXPERIÊNCIA DAS EMPRESAS JUNIORES DA UNIVERSIDADE DE BRASÍLIA
}

Valmir Emil Hoffmann ${ }^{1}$

David Leonardo Bouças Da Silva ${ }^{2}$

Diogo Barbosa Silva ${ }^{1}$

\footnotetext{
${ }^{1}$ Universidade de Brasília

${ }^{2}$ Universidade Federal do Maranhão
} 


\section{VISÃO BASEADA EM RECURSOS NO CONTEXTO ACADÊMICO: A EXPERIÊNCIA DAS EMPRESAS JUNIORES DA UNIVERSIDADE DE BRASÍLIA}

Resumo: Este trabalho objetiva identificar os recursos competitivos empregados pelas empresas juniores da Universidade de Brasília, pautado na Visão Baseada em Recursos Modelo VRIO (Barney \& Hesterly, 2007). As 12 EJs, alvo de investigação, foram aquelas pertencentes à Universidade de Brasília. Metodologicamente, este consiste em um estudo descritivo, de abordagem qualitativa, realizado em 2018, com as empresas em comento. Para coleta e análise de dados, utilizou-se um roteiro semiestruturado, cujas entrevistas gravadas foram interpretadas a partir da técnica de Análise de Conteúdo (Bardin, 1977). Os resultados apontaram que os recursos financeiros (estrutura de custo) e individuais (flexibilidade de escopo) não são fontes de vantagem competitiva, diferentemente dos físicos (Laboratórios e equipamentos) e organizacionais (Reputação e relacionamentos), os quais advêm da própria Universidade e que garantem diferencial competitivo. Por fim são apresentadas as limitações do estudo, assim como as sugestões de estudos futuros.

Palavras-chave: Estratégia Empresarial. Recursos Competitivos. Empresas Juniores. Universidade de Brasília.

\section{$1 \quad$ Introdução}

O mercado de Empresas Juniores (EJs) no Brasil se mostra de grande relevância, uma vez que há uma preocupação recorrente entre os universitários para que oportunidades de exercitar os conteúdos aprendidos em sala de aula e angariar experiências no mercado sejam criadas (Feitosa \& Firmo, 2013). Parte dessas possibilidades de atuação profissional, em estágio prévio à formação acadêmica, materializa-se, por meio da imersão nas EJs (Rodrigues et al., 2010).

O Movimento Empresa Junior (MEJ) é formado por cerca de 20 mil universitários, os quais atuam em mais de 600 EJs vinculadas à Confederação Brasileira de Empresas Juniores (Brasil Junior, 2018). Estas EJs possuem uma regulamentação específica, a Lei N 13.267/16 (Brasil, 2016). As Ejs são formadas por jovens estudantes de graduação, que atuam em um ambiente de alta competitividade, sobretudo consultoria. Ainda assim, em 2016, as EJs movimentaram $\mathrm{R} \$ 16,4$ milhões, por meio de projetos de consultoria no Brasil (Brasil Junior, 2018), o que comprova a força do MEJ e se mostra oportuno para o desenvolvimento de estudos mais aprofundados.

Dados obtidos no contexto nacional demonstram que algumas EJs aumentaram o seu faturamento em cerca de 20\% entre os anos de 2015 e 2017 (Brasil Junior, 2018). Contudo, ressalva-se que este resultado positivo não é alcançado por todas elas. A incerteza sobre o que diferencia essas empresas, em termos dos seus recursos competitivos, suscita importantes debates e conduzem à seguinte pergunta de pesquisa: Quais são os recursos competitivos existentes em EJs?

A partir desta indagação, traz-se o objetivo deste estudo: identificar os recursos competitivos empregados pelas empresas juniores da Universidade de Brasília. Para tanto, 
lança-se mão do Modelo VRIO, proposto por Barney e Hesterly (2007), para viabilizar a análise dos recursos estratégicos das EJs investigadas. Isto posto, reforça-se que este estudo se pauta na Visão Baseada em Recursos (VBR), originalmente Resource-based View (RBV), enquanto um modelo de desempenho com foco nos recursos e nas capacidades controladas por uma empresa como fontes de vantagem competitiva (Barney \& Hesterly, 2007).

A relevância deste trabalho encontra respaldo nas sugestões de pesquisa de Aragão, Forte e Oliveira (2010), para os quais há uma defasagem de 14 anos das pesquisas sobre VBR no Brasil em relação ao contexto internacional e, portanto, recomendaram o aprofundamento da produção sobre este tema no país, para além de estudos de caso. Corroboraram Pavão, Sehnem e Hoffmann (2011), ao recomendarem que o modelo VRIO seja replicado em diferentes contextos, setores de atuação e ambientes de trabalho.

\section{Recursos Estratégicos como Fonte de Vantagem Competitiva}

A atuação estratégica de cada empresa é defendida de diferentes formas, conforme os mais variados autores. Alguns deles de maneira, mais seminal, pautaram-se em compreensões teóricas que remetem aos recursos internos da firma (Barney, 1991; Penrose, 1959; Peteraf, 1993; Selznick, 1957; Wernerfelt, 1984), enquanto outros às pressões e desafios impostos pelo ambiente externo (Porter, 1986, 1991). Há aqueles que compreendem a necessidade de focar nas suas articulações externas - relacionamentos interorganizacionais - para obter recursos extra-firma necessários à sua competitividade (Thorelli, 1986; Jarillo, 1988).

Das abordagens citadas, a da Visão Baseada em Recursos (VBR) é uma das correntes de pensamento contemporâneas mais importantes do campo da estratégia empresarial (Gohr et al., 2011). A VBR norteia o presente estudo, dada a compreensão de que os recursos tangíveis ou intangíveis - controlados pelas firmas e sua utilização produtiva são relevantes fontes de vantagem competitiva (Barney \& Hesterly, 2007; Hoskisson, 2000). Isto porque as firmas, em uma dada indústria, são heterogêneas quanto aos recursos estratégicos que gerenciam (heterogeneidade de recursos), e estes recursos não são perfeitamente móveis (imobilidade dos recursos) entre elas (Barney, 1991, 2001). Se, de alguma forma, os recursos rendem resultados extraordinários (Brito \& Vasconcelos, 2004) - ou seja, são raros, escassos, especializados, complementares e capazes de adicionar valor efetivo às organizações - eles têm potencial para gerar desempenho superior (Hexsel, De Toni, Wilk \& Larentis, 2008).

Conceitualmente, os recursos são caracterizados como os ativos, competências, informações, processos organizacionais e demais atributos gerenciados pela firma, os quais propiciam a criação e implementação de estratégias que melhorem sua eficiência e eficácia e que sejam sustentadas por mais tempo (Daft, 1983). Com maior amplitude, Wernerfelt (1984) definiu recursos como todos os ativos tangíveis e intangíveis, a exemplo de equipamentos, marcas, tecnologias, habilidades dos indivíduos pertencentes à organização, processos etc. Para Porter (1986), recursos são as forças que as firmas utilizam para conceber e implementar suas estratégias.

No que tange à classificação dos recursos, a priori, apresenta-se a proposta de Grant (1991). Este autor categorizou os recursos em tangíveis, aqueles mais facilmente observáveis, tais como equipamentos e pessoas, e intangíveis, mais difíceis de identificar e quantificar, a exemplo das suas capacidades dinâmicas (Teece, Pisano \& Shuen, 1997), conhecimento, reputação e cultura organizacional (Hexsel et al., 2008), além de relacionamentos (Hoffmann, 
Vieira, Reyes Jr. \& Melo, 2015). Barney e Hesterly (2007) estabeleceram a classificação que norteia o presente estudo: Financeiros, Físicos, Humanos e Organizacionais (Tabela 1).

\section{Tabela 1}

Classificação de Recursos Estratégicos

\begin{tabular}{|c|l|}
\hline TIPO DE RECURSO & \multicolumn{1}{|c|}{ DEFINIÇÃO } \\
\hline Financeiros & $\begin{array}{l}\text { Abrangem todas as fontes de dinheiro utilizadas pela firma para criar e } \\
\text { implementar as suas estratégias. Eles podem provir de empreendedores, acionistas, } \\
\text { instituições financiadoras e dos próprios clientes. }\end{array}$ \\
\hline Físicos & $\begin{array}{l}\text { Equivalem à tecnologia física, a qual inclui os equipamentos, máquinas, } \\
\text { localização geográfica etc. }\end{array}$ \\
\hline Individuais & $\begin{array}{l}\text { Correspondem ao treinamento, experiência, visão e habilidades individuais dos } \\
\text { colaboradores de cada setor da organização. }\end{array}$ \\
\hline Organizacionais & $\begin{array}{l}\text { Caracterizados pela interação de grupos de pessoas, incluindo os sistemas formais } \\
\text { e informais de planejamento, controle e coordenação, bem como a cultura e a } \\
\text { reputação da empresa. }\end{array}$ \\
\hline
\end{tabular}

Fonte: Barney (1991); Barney e Hesterly (2007).

Uma das maneiras de aplicar a VBR ocorre por meio da identificação dos recursos e sua inserção no modelo VRIO (Pavão et al., 2011). Nele, Barney e Hesterly (2007) estabeleceram que quando os recursos estratégicos da firma são Raros (R), Valiosos (V), Difíceis de imitar (I) e Organizáveis $(\mathrm{O})$ podem gerar vantagens competitivas sustentáveis. Estes autores orientam para que se questione cada atributo ao se aplicar o modelo: i. Valor: recursos e capacidades possibilitam que a firma responda a ameaças externas ou oportunidades?; ii. Raridade: o recurso é controlado somente por poucas empresas concorrentes?; iii. Imitabilidade: as firmas desprovidas do recurso enfrentam desvantagens em obter ou desenvolver este recurso?; iv. Organização: políticas e procedimentos são/estão organizados para apoiar a utilização de recursos valiosos, raros e difíceis de imitar? (Tabela 2).

\section{Tabela 2}

Modelo VRIO

\begin{tabular}{|c|c|c|c|c|c|}
\hline \multicolumn{6}{|c|}{ O recurso ou capacidade é... } \\
\hline $1^{\circ}$ passo & $2^{\circ}$ passo & $3^{\circ}$ passo & $4^{\circ}$ passo & Resultados & Resultados \\
\hline Valioso? & Raro? & $\begin{array}{l}\text { Difícil de } \\
\text { imitar? }\end{array}$ & Organizável & Implicações competitivas & $\begin{array}{c}\text { Desempenho } \\
\text { econômico }\end{array}$ \\
\hline Não & - & - & \multirow{4}{*}{ Não } & Desvantagem competitiva & $\begin{array}{l}\text { Abaixo do } \\
\text { Normal }\end{array}$ \\
\hline Sim & Não & - & & $\begin{array}{c}\text { Paridade Competitiva } \\
\text { Temporária }\end{array}$ & Normal \\
\hline Sim & Sim & Não & & $\begin{array}{l}\text { Vantagem Competitiva } \\
\text { Temporária }\end{array}$ & $\begin{array}{l}\text { Acima do } \\
\text { Normal }\end{array}$ \\
\hline Sim & Sim & Sim & & $\begin{array}{c}\text { Vantagem Competitiva } \\
\text { Sustentável }\end{array}$ & $\begin{array}{l}\text { Acima do } \\
\text { Normal }\end{array}$ \\
\hline
\end{tabular}

Fonte: Adaptado de Barney e Hesterly (2007).

Conforme se observa acima, a raridade do recurso e o valor dele não são suficientes para obtenção de vantagens competitivas. Faz-se necessário que estes recursos não sejam facilmente imitados/substituídos pelos concorrentes e que, do mesmo modo, a firma 
individual saiba como explorar o potencial competitivo dos seus recursos estratégicos (Barney, 1991, 2001; Barney \& Herstely, 2007). Para Gohr et al. (2011), a questão central da VBR é a forma como as firmas se distinguem no alcance e sustentação de vantagens competitivas, por meio da exploração de seus recursos.

O entendimento de que a VBR auxilia os tomadores de decisão acerca do papel que os recursos possuem na geração de vantagem competitiva (Peteraf, 1993; Pavão et al., 2011) estimulou variados autores a desenvolverem suas investigações em diferentes setores e âmbitos consubstanciados no tema. Sucintamente, traz-se que Sanches e Machado (2013), ao analisarem as estratégias inovativas de uma empresa de base tecnológica, concluíram que know-how, design da estrutura, cultura, modo como os projetos são feitos e capacidade empreendedora são os recursos centrais para a inovação.

Alves, Pizzinato e Gonçalves (2010), em seu estudo com redes imobiliárias brasileiras, verificaram que relacionamentos se mostram um importante recurso estratégico para acessar os recursos externos dos seus parceiros. No contexto internacional, Rijnsoever, Hessels e Vandeberg (2008) identificaram que alianças com outros pesquisadores são fundamentais para um crescimento de carreira. Resultado similar foi identificado por Jaafar \& Abdul-Aziz (2005) na realidade de pequenas e médias empresas da Malásia para que estas alcancem vantagem competitiva. Reúne-se, abaixo, outros estudos que aplicaram o modelo VRIO em distintas realidades organizacionais (Tabela 3 ).

Tabela 3

Aplicações do Modelo VRIO

\begin{tabular}{|c|l|c|c|}
\hline \multirow{2}{*}{ Autores } & \multicolumn{1}{|c|}{ Objetivo } & Recursos Encontrados & Tipo de \\
Recurso
\end{tabular}




\begin{tabular}{|c|c|c|c|}
\hline & $\begin{array}{l}\text { VRIO e identificar as implicações } \\
\text { competitivas dos recursos nas } \\
\text { organizações }\end{array}$ & $\begin{array}{c}\text { Cultura e Reputação; Sistemas formais } \\
\text { e informais }\end{array}$ & Organizacional \\
\hline \multirow{4}{*}{$\begin{array}{l}\text { Oliveira e } \\
\text { Forte }(2011)\end{array}$} & \multirow{4}{*}{\begin{tabular}{lrrr} 
Identificar & os & \multicolumn{2}{c}{ recursos } \\
utilização mais & provável pelos \\
bancos, ante & os & cenários \\
construídos para a & indústria \\
bancária brasileira & &
\end{tabular}} & $\begin{array}{c}\text { Pessoal qualificado, gestão de talentos } \\
\text { e competência }\end{array}$ & Individual \\
\hline & & $\begin{array}{c}\text { Alta qualidade dos produtos e serviços } \\
\text { prestados; Atendimento personalizado } \\
\text { e relacionamento com o cliente; } \\
\text { Administração de recursos de } \\
\text { terceiros; Melhoria da qualidade da } \\
\text { carteira de crédito } \\
\end{array}$ & Organizacional \\
\hline & & $\begin{array}{l}\text { Serviço bancário on-line; Serviços de } \\
\text { cartão de crédito }\end{array}$ & Físico \\
\hline & & Empréstimos a pessoa física & Financeiro \\
\hline \multirow{3}{*}{$\begin{array}{l}\text { Silva et al. } \\
\quad(2011)\end{array}$} & \multirow{3}{*}{$\begin{array}{l}\text { Entender como priorizar os } \\
\text { critérios competitivos em que a } \\
\text { empresa deseja incrementar a } \\
\text { vantagem ou recuperar a } \\
\text { defasagem sobre os concorrentes, } \\
\text { considerando os recursos } \\
\text { competitivos que ela possa ter } \\
\text { acesso. }\end{array}$} & $\begin{array}{l}\text { Direção empreendedora; } \\
\text { conhecimento e experiência }\end{array}$ & Individual \\
\hline & & $\begin{array}{l}\text { Sinergia entre empresas do grupo; } \\
\text { transferência de tecnologia entre as } \\
\text { unidades; sistema de controle de } \\
\text { qualidade; logística integrada }\end{array}$ & Organizacional \\
\hline & & Sistema de engenharia & Físico \\
\hline
\end{tabular}

Fonte: elaboração própria, a partir das fontes indicadas.

Embora em realidades e organizações distintas, determinados recursos têm se mostrado como fonte de vantagens competitivas, seja no contexto de micro, pequenas ou médias empresas. No entanto, não se encontrou na revisão de literatura a aplicação da VBR para o contexto de empresas juniores. Neste aspecto, o presente trabalho avança, a fim de identificar quais são os recursos estratégicos para organizações desta natureza.

\section{$3 \quad$ Metodologia}

Esta constitui uma pesquisa descritiva, bibliográfica e de campo (Vergara, 1997), com caráter transversal e qualitativo (Flick, 2009), realizado junto a 12 empresas juniores (Tabela 4) das 38 existentes atualmente na Universidade de Brasília. Os públicos entrevistados foram os presidentes das EJs, em decorrência da sua participação direta e ativa na gestão estratégica e tomada de decisão das empresas. Dada a heterogeneidade das EJs, abarcou-se as mais diversas áreas de atuação: Administração, Economia, Engenharias, Biotecnologia, Computação e Psicologia. Indica-se, também, a maturidade da cada EJ - de 1 a 5 em ordem crescente (Brasil Júnior, 2018) - a qual leva em conta dados de faturamento, tempo médio de projeto e número de membros ativos (Tabela 4).

\section{Tabela 4}

Caracterização da Amostra

\begin{tabular}{|c|c|c|c|c|}
\hline EJ/N & Curso & \multicolumn{1}{|c|}{ Descrição dos serviços } & $\begin{array}{c}\text { Tempo de } \\
\text { existência }\end{array}$ & Cluster \\
\hline EJ1 & Administração & $\begin{array}{l}\text { Especializada em problemas de gestão de empresas, } \\
\text { com enfoque nas áreas de Marketing, Finanças, } \\
\text { Organização e Processos, e Gestão de Pessoas. }\end{array}$ & 27 anos & 5 \\
\hline EJ2 & Computação & Projetos inovadores em TI. Oferecem cursos e & 20 anos & 3 \\
\hline
\end{tabular}




\begin{tabular}{|c|c|c|c|c|}
\hline & & $\begin{array}{l}\text { treinamentos de tecnologia de Desenvolvimento Web e } \\
\text { ferramentas computacionais. }\end{array}$ & & \\
\hline EJ3 & Turismo & $\begin{array}{l}\text { Consultoria Turística, projetos sobre planejamento } \\
\text { turístico, empreendedorismo e eventos, Gastronomia e } \\
\text { Hotelaria. }\end{array}$ & 4 anos & 1 \\
\hline EJ4 & $\begin{array}{l}\text { Comunicação } \\
\text { Social }\end{array}$ & $\begin{array}{l}\text { Agência de publicidade júnior que elabora planos de } \\
\text { campanha para diferentes negócios. }\end{array}$ & 23 anos & 2 \\
\hline EJ5 & $\begin{array}{l}\text { Engenharia } \\
\text { Química }\end{array}$ & $\begin{array}{l}\text { Presta consultoria e realiza serviços em tecnologias } \\
\text { químicas. }\end{array}$ & 5 anos & 4 \\
\hline EJ6 & $\begin{array}{l}\text { Engenharia } \\
\text { Civil }\end{array}$ & $\begin{array}{l}\text { Soluções personalizadas em Arquitetura, Engenharia } \\
\text { Civil e Engenharia Ambiental. }\end{array}$ & 21 anos & 4 \\
\hline EJ7 & Geofísica & Soluções em Geofísica e Geotecnologia. & 9 anos & 3 \\
\hline EJ8 & Psicologia & $\begin{array}{l}\text { Atua na área de Consultoria em Gestão de Pessoas com } \\
\text { serviços personalizados e de alta qualidade. }\end{array}$ & 24 anos & 4 \\
\hline EJ9 & Biotecnologia & $\begin{array}{l}\text { Análise de água, microbiológica de alimentos e } \\
\text { bebidas, gerenciamento de resíduos, otimização de } \\
\text { processos industriais, boas práticas, biossegurança etc. }\end{array}$ & 20 anos & 1 \\
\hline EJ10 & $\begin{array}{l}\text { Engenharia de } \\
\text { Redes de } \\
\text { Comunicação }\end{array}$ & $\begin{array}{l}\text { Otimização de Rede; Cabeamento Estruturado; } \\
\text { Instalação de servidores. }\end{array}$ & 10 anos & 2 \\
\hline EJ11 & $\begin{array}{c}\text { Ciências } \\
\text { Econômicas }\end{array}$ & Soluções em Consultoria Econômica. & 19 anos & 5 \\
\hline EJ12 & Direito & $\begin{array}{l}\text { Consultoria jurídica, compliance, contratos, direito } \\
\text { empresarial, civil, administrativo, privado, de família, } \\
\text { licitações, pesquisas jurídicas, patente etc. }\end{array}$ & 4 anos & 3 \\
\hline
\end{tabular}

Fonte: Pesquisa de campo; Brasil Júnior (2018); Concentro (2018).

Os procedimentos para coleta de dados foram realizados, inicialmente, a partir do levantamento das EJs da UnB inserida no sítio eletrônico da Brasil Júnior; identificação dos presidentes dessas EJs; realização de entrevistas semiestruturadas e presenciais, em visita a cada empresa, cujo duração média era de 30 minutos. A elaboração do roteiro semiestruturado se baseou em Barney e Hesterly (2007), cujos questionamentos se relacionavam aos recursos das EJs, suas formas de atuação, relacionamento com o mercado e demais stakeholders (Tabela 5). Para determinação dos sujeitos se seguiu o critério de adesão e saturação teórica (Fontanella, Ricas \& Turato, 2008).

\section{Tabela 5}

Roteiro Semiestruturado

\begin{tabular}{|c|l|}
\hline Tipo de recurso & \multicolumn{1}{c|}{ Perguntas semiestruturadas } \\
\hline \multirow{3}{*}{ Financeiros } & Quais são os principais custos da empresa? \\
& Como funciona a gestão tributária de uma EJ? \\
& As EJs têm direito à isenção de impostos? \\
& Quais são as principais fontes de receita da EJ? \\
& Como vocês precificam seus produtos e serviços? \\
\hline \multirow{2}{*}{ Físicos } & A EJ possui um ambiente fixo de trabalho? \\
& Como este ambiente funciona? \\
& O que é necessário para prestação dos seus serviços? \\
& Como a localização da EJ pode influenciar nos seus produtos e serviços? \\
\hline
\end{tabular}




\begin{tabular}{|c|c|}
\hline Individuais & $\begin{array}{l}\text { Como são os treinamentos dos membros da EJ? } \\
\text { Como é o atendimento ao cliente? } \\
\text { Como funciona o seu processo de venda? }\end{array}$ \\
\hline Organizacionais & $\begin{array}{l}\text { Como seu portfólio de serviços é definido? } \\
\text { Como a cultura de uma EJ pode influenciar nos seus resultados? } \\
\text { Como é o relacionamento com os seus stakeholders? } \\
\text { Na sua visão, qual é o seu diferencial de mercado? } \\
\text { Como o mercado enxerga a empresa de vocês? }\end{array}$ \\
\hline
\end{tabular}

Fonte: Elaboração própria baseado em Barney e Hesterly (2007).

O registro das falas se deu, em dezembro de 2018, por meio da gravação consentida pelos entrevistados. O conteúdo transcrito foi transferido para uma planilha Excel, onde os dados foram subdivididos em quatro categorias de recursos pautadas em Barney e Hesterly (2007): financeiros; físicos; individuais; e organizacionais. A técnica de análise de dados utilizada foi a Análise de Conteúdo, do tipo categorial a priori, conforme Bardin (1977). Por fim, aplicou-se o modelo VRIO de Barney e Hesterly (2007) para identificar os recursos competitivos das EJs.

\section{$4 \quad$ Resultados e discussões}

Os recursos identificados são apresentados no Tabela 6 abaixo. No total, são seis recursos subdivididos na classificação proposta por Barney e Hesterly (2007). Estes foram levantados como relevantes e estratégicos para as suas EJs, passíveis de potencialização ou melhor exploração para gerarem vantagens competitivas. A posteriori, estes recursos estratégicos são analisados no modelo VRIO.

Tabela 6

Recursos Estratégicos

\begin{tabular}{|c|c|c|}
\hline & Recursos & Classificação \\
\hline \multicolumn{2}{|r|}{ Estrutura de Custo - Preço } & \multirow{9}{*}{ Financeiro } \\
\hline EJ1 & $\begin{array}{l}\text { Geralmente os clientes procuram a gente por algumas razões: a primeira é preço } \\
\text { competitivo com o mercado [...] a gente costuma ter preços mais competitivos do } \\
\text { que empresas de mercado de consultoria já que o nosso fim não é lucrativo. }\end{array}$ & \\
\hline EJ2 & Um dos maiores fatores é o preço também, porque o nosso é bem mais barato. & \\
\hline EJ4 & $\begin{array}{l}\text { Nossos preços são bem abaixo dos praticados no mercado. Mas a gente tem que } \\
\text { ser até } 20 \% \text { do mercado. }\end{array}$ & \\
\hline EJ5 & $\begin{array}{l}\text { Nosso mercado é bem escasso em Brasília, principalmente }[\ldots] \text { área de consultoria. E } \\
\text { por ser EJ, acho que eles veem como uma opção de preço mais baixo. }\end{array}$ & \\
\hline EJ6 & "A grande maioria busca preços mais acessíveis". & \\
\hline EJ9 & $\begin{array}{l}\text { Em relação à análise microbiológica, é um serviço muito caro que no mercado eles } \\
\text { não têm muita opção. Então, a gente oferece um serviço de qualidade e com } \\
\text { menor preço. Acho que isso é um diferencial. }\end{array}$ & \\
\hline EJ10 & $\begin{array}{l}\text { Hoje eu acho que os clientes procuram a gente, por }[. . .] \text { ter um preço abaixo do } \\
\text { mercado [...] A média no mercado é muito mais cara do que o que a gente passa. }\end{array}$ & \\
\hline EJ12 & $\begin{array}{l}\text { [...] uma das principais é o preço mais acessível. Os advogados estão sujeitos à } \\
\text { tabela da OAB e a gente não tem essa restrição, até porque somos estudantes, sem } \\
\text { fins lucrativos [...] Isso inclusive faz parte da nossa missão. }\end{array}$ & \\
\hline & Estrutura de Custos - Custos & Classific \\
\hline
\end{tabular}


EJ1 Wi-fi [..] muitos custos que seriam relacionados à infraestrutura do espaço físico são custeados ainda pela UnB. Isso ajuda bastante a gente.

EJ6 Temos só conta de internet, por opção nossa. O resto é por conta da Universidade mesmo.

EJ7 A gente não tem custo assim para manter a empresa. A gente tem custo com conta Google, às vezes com advogado, mas nada fora disso.

Custo fixo é a parte burocrática de contador, semestralidade da Concentro, site

EJ9 também. Custos de projeto, variável, é reagente, deslocamentos, impressões. Nossos custos são menores, não pagamos salários.

Custo fixo [...] é o contador, semestralidade da concentro, taxas de banco. Não

EJ11 são muitas coisas, é bem tranquilo. Não pagamos contas de luz, água. A gente paga hospedagem do site também. Telefone também não, internet a gente puxa a da UnB.

\begin{tabular}{|l|l|}
\hline \multicolumn{2}{|c|}{ Estrutura de Custos - Isenção de Impostos } \\
\hline EJ4 & Por ser EJ, temos condições melhores em relação aos impostos. \\
\hline EJ5 & $\begin{array}{l}\text { A gente paga só ISS e COFINS, em torno de } 12,6 \% \text {. Por não ter fins lucrativos, a } \\
\text { gente tem algumas isenções. }\end{array}$ \\
\hline EJ6 & A gente paga só 12,6\% de imposto por ser EJ. \\
\hline EJ7 & {$[\ldots]$ só ISS e COFINS, que dá $12,6 \%$.} \\
\hline
\end{tabular}

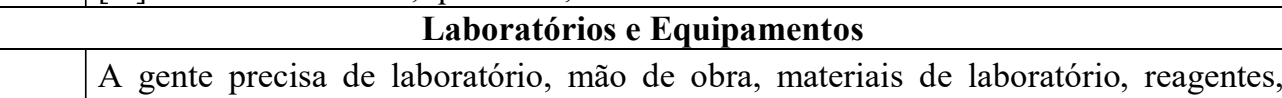

Classificação

Financeiros EJ5 professores, responsável técnico e cadastro no CRQ. E tem o laboratório também, que os professores deixam a gente utilizar.

A gente tem parceria com o Instituto de Geociências e utiliza os equipamentos deles. São equipamentos muito caros que uma EJ não tem condições de comprar [...] de uns R\$ 500 mil [...] não é rentável para a empresa (contratante) comprar só para realizar um projeto e depois inutilizar [...] Isso é uma vantagem também em relação ao mercado, porque como temos acesso aos equipamentos caros aqui do Instituto [...] que as empresas não têm, eles basicamente contratam a gente.

A gente precisa de estrutura, de laboratório [...] contamos muito com o apoio dos EJ9 professores e do Instituto de Biologia [...] para usar os laboratórios. Precisamos de equipamentos [...] específicos para realizar as análises e o projeto [...] de forma gratuita.

\section{Cultura e engajamento} Acredito muito nesse diferencial, na vontade de aprender, de correr atrás, espírito jovem. Algo que não é costume mesclar o que aprende na faculdade com o que é possível fazer.

A galera aqui está muito disposta a aprender, pessoal gosta. Quando chega um

EJ2 projeto diferente, a galera toda quer fazer, independente da dificuldade. Então, acho que esse é nosso principal diferencial, vontade de aprender, fazer coisa nova.

A gente tem um outro olhar em relação às empresas seniores. Acho que isso vem
muito da paixão pela publicidade. O brilho no olho, o que não é tão fácil de achar no mercado, porque muitas vezes a pessoa está ali só porque ela fez um curso e se especializou naquilo $[. .$.$] a gente quer aprender cada vez mais.$

Todos que estão aqui realmente amam o que fazem. Têm um senso de dono,

EJ6 dedicação pela empresa muito grande. A EJ tem uma cultura organizacional muito boa, todos aqui realmente amam o que fazem.

EJ9 Acho que a vontade de realizar [...] Como membros da empresa, essa vontade de fazer a EJ acontecer e de querer fazer os serviços que a EJ se propõe a fazer. 


\begin{tabular}{|c|c|c|}
\hline EJ11 & $\begin{array}{l}\text { Hoje, vejo o que é muito da nossa vontade de aprender. As pessoas que estão aqui } \\
\text { querem muito aprender, investir o tempo delas [...] acho que essa fome mesmo de } \\
\text { aprendizado, porque muitas coisas que a gente vê aqui, a gente não vê lá no curso. }\end{array}$ & \\
\hline \multicolumn{2}{|r|}{ Flexibilidade de escopo } & Classificação \\
\hline EJ2 & $\begin{array}{l}\text { Um cliente chegou aqui e pediu um site. Aí, procuramos leiaute e fizemos várias } \\
\text { coisas além do nosso trabalho. Queremos sempre fazer o melhor para o cliente. }\end{array}$ & \multirow[b]{2}{*}{ Individual } \\
\hline EJ6 & $\begin{array}{l}\text { Hoje, no mercado você não encontra um dinamismo tão grande para flexibilizar } \\
\text { o escopo, até porque o mercado está muito pautado no lucro. A EJ também, mas a } \\
\text { gente quer ter uma experiência de capacitação muito maior. }\end{array}$ & \\
\hline \multicolumn{2}{|r|}{ Universidade - Reputação } & Classificação \\
\hline EJ1 & $\begin{array}{l}\text { Procuram muito a gente também por a gente estar situado na UnB, por ser uma } \\
\text { Universidade de renome. Deles saberem que a gente tem o apoio dos professores } \\
\text { do departamento }[\ldots] \text { procuram muito a nossa EJ pela sua história, a gente foi a } \\
\text { pioneira no DF }[. . .] \text { já realizou mais de } 600 \text { projetos ao longo da nossa história. }\end{array}$ & \multirow{3}{*}{ Organizacional } \\
\hline EJ8 & $\begin{array}{l}\text { Essa demanda passiva que a gente tem, vem muito pelo peso da Psicologia } \\
\text { Organizacional da UnB. A gente tem os principais nomes da área aqui no Instituto } \\
\text { de Psicologia }[\ldots] \text { fundadores da nossa EJ [...] trabalham com a gente, apoiam e } \\
\text { orientam os projetos. Já passei por situações de um possível cliente perguntar se } \\
\text { eu ia trabalhar com determinado professor antes de fechar o contrato. }\end{array}$ & \\
\hline EJ12 & Pelo fato da gente estar aqui na Universidade, polo de conhecimento. & \\
\hline \multicolumn{2}{|r|}{ Universidade - Relacionamentos } & Classificação \\
\hline EJ3 & $\begin{array}{l}\text { A proximidade com a Universidade. Nós somos muito próximos do nosso } \\
\text { departamento e isso é uma coisa que traz uma certa credibilidade para a gente. }\end{array}$ & \multirow{3}{*}{ Organizacional } \\
\hline EJ7 & $\begin{array}{l}\text { Os professores atuam bastante. A gente apresenta a metodologia, precificação do } \\
\text { projeto e eles sempre têm algo a criticar [...] temos muito suporte dos professores. }\end{array}$ & \\
\hline $\mathrm{EJ} 12$ & $\begin{array}{l}\text { Todos os nossos conselheiros (orientadores) são advogados de muito renome, } \\
\text { então eles atraem muitos projetos. }\end{array}$ & \\
\hline
\end{tabular}

Fonte: Elaboração própria a partir de dados da pesquisa.

Primeiramente, no que concerne aos recursos financeiros, traz-se que os custos reduzidos e a isenção de impostos favorecem que as EJs cheguem à oferta de preços competitivos em relação ao mercado (estrutura de custo). Os atributos "Custos" e "Isenção de impostos" são menos comuns no mercado, todavia algo inerente à realidade das EJs, conforme rege a Lei 13.267/16. As EJs não possuem alguns dos elevados custos peculiares às empresas comuns - encargos trabalhistas, aluguel de espaço físico, equipamentos etc. - por serem entidades sem fins lucrativos e as instituições de ensino apoiarem disponibilizando tais insumos.

"Preços" são compreendidos pela maioria das EJs entrevistadas como um dos fatores centrais da atratividade das EJs em comparação às demais organizações do seu mercado atuação. Este resultado, presente também nos estudos de Pavão et al. (2011), Hermes et al. (2015), Fonseca e Cunha (2015) indica que os recursos financeiros podem ser estratégicos e valiosos para empresas atuantes em setores e mercados diversos. Este recurso favorece às EJs, do mesmo modo, a possibilidade de transacionar com os mais diversos tipos de clientes - de empresas de grande porte ou órgãos públicos - inclusive, quando se trata da realidade das micro e pequenas empresas, as quais, ceteris paribus, possuem reduzida capacidade operacional e de investimentos (Balestrin \& Vargas, 2004; Verschoore, Balestrin \& Perucia, 2014). Complementarmente, Pavão et al. (2011) sinalizaram que um recurso financeiro 
valioso pode se tornar um ponto importante de vantagem competitiva, quando combinado com recursos estratégicos de outras categorias e vice-versa.

No que tange aos recursos físicos, identificou-se para três EJs da UnB - Engenharia Química, Geofísica e Biotecnologia - a existência de "Laboratórios e Equipamentos" como diferenciais competitivos, conforme observado na pesquisa de Fonseca e Cunha (2015), em empresas na área de TI, e Gohr et al. (2011) no setor sucroalcooleiro. O fato de serem atreladas ao ambiente universitário, por meio de seus cursos, as EJs podem acessar, gratuitamente, equipamentos, materiais e laboratórios, por vezes, raros no mercado. Esta fala foi ressaltada pela EJ7 quanto aos custos para aquisição de equipamentos que inviabiliza que determinadas empresas consigam realizar seus projetos sem a ajuda de um terceiro. De maneira diametralmente oposta, esta oportunidade de utilização dos equipamentos e laboratórios que geram vantagem competitiva às EJs da UnB não foi identificada na pesquisa de Feitosa e Firmo (2013) com duas EJs da UFPE.

Quanto aos recursos individuais, verificou-se a "Flexibilidade de Escopo", que consiste na disposição dos participantes das empresas juniores em proporcionar um melhor resultado para o cliente, mesmo que isso signifique sair do escopo contratado. Diante de um mercado que exige, há muito, personalização no atendimento ao consumidor (Lee \& Lin, 2005), as EJs conseguem ampliar a sua percepção de valor com base em um atendimento que se volte mais às necessidades do seu cliente, visando a geração de resultados e satisfação. Nesse caso, vale ressaltar que o foco principal de uma EJ não é o lucro, mas sim o desenvolvimento pessoal e profissional dos seus membros por meio de projetos (Silva, Almeida e Ferreira, 2015).

Por último, os recursos organizacionais encontrados nas empresas juniores estudadas foram "Universidade - reputação e relacionamentos" e "Cultura e Engajamento". O recurso "Cultura e Engajamento" foi apontado pelos participantes do estudo como a representação do espírito jovem, inovador e empreendedor das EJs, por meio dos seus membros e do ambiente em que estão inseridas. No que diz respeito à cultura organizacional, este recurso também foi encontrado na literatura, onde Pavão et al. (2011) identificaram o seu potencial de fazer com que a empresa seja bem vista pelos seus stakeholders.

Quanto ao "Engajamento", este se assemelha aos recursos encontrados por Oliveira e Forte (2011), o qual citou o recurso "pessoal qualificado, gestão de talentos e competência" como vantagem competitiva nas indústrias bancárias. E Gohr et al. (2011) apontaram o recurso "mão de obra qualificada". Ambos convergem para sentido similar ao recurso "Engajamento" identificado neste trabalho, uma vez que estão diretamente relacionados aos recursos humanos das empresas. Isso indica que, em diferentes mercados, aspectos e competências, os recursos humanos se apresentam como ponto relevante e passível de diferenciação e vantagem competitiva entre as empresas. Ademais, este resultado dialoga com os achados de Feitosa e Firmo (2013), para os quais os acadêmicos do MEJ se comprometem de maneira afetiva com as empresas juniores, diante da oportunidade de aplicarem os seus conhecimentos adquiridos em sala de aula.

O recurso "Universidade" também traz dois atributos principais: reputação e relacionamentos. Reputação converge diretamente com o trabalho de Bezerra et al. (2015), Fonseca e Cunha (2015), Hexsel et al. (2008), e indiretamente para os trabalhos de Hermes et al. (2016) e Gohr et al. 2011). Estes dois últimos autores elencaram a "localização" ou "localização privilegiada" como um recurso de vantagem competitiva nos mercados varejista 
e sucroalcooleiro, respectivamente. Justificam este resultado com base em razões logísticas que possibilitam agilidade e redução de custos nos mercados por eles estudados. No caso das EJs investigadas, reputação e localização se unem de maneira valiosa por se tratar de um polo acadêmico reconhecido como a $15^{\text {a }}$ universidade de maior prestígio da América Latina (The Higher Education, 2019). A construção de reputação requer tempo, o que faz com que este recurso seja uma fonte de vantagem competitiva.

Em se tratando de relacionamentos (recurso Universidade), este ocorre pela proximidade com os departamentos dos cursos, professores, ex-membros e empresas de mercado que apoiam as EJs. O que, de acordo com variados autores (Alves et al., 2010; Hoffmann et al., 2015; Jaafar \& Abdul-Aziz, 2005; Rijnsoever et al., 2008), é um recurso que propicia vantagem competitiva. Alguns professores são vistos pelo mercado como grandes especialistas em determinados assuntos, e isso faz com que, estando próximas e tendo bom relacionamento com eles, as EJs atraiam clientes e projetos relevantes.

Identificados os recursos estratégicos, parte-se para a aplicação do Modelo VRIO, conforme apresentado no Tabela 7 abaixo.

Tabela 7

Modelo VRIO - Recursos Competitivos

\begin{tabular}{|c|c|c|c|c|c|}
\hline Recurso & Valioso? & Raro? & $\begin{array}{c}\text { Difícil de } \\
\text { imitar? }\end{array}$ & $\begin{array}{c}\text { Explorado } \\
\text { pela EJ? }\end{array}$ & Resultado \\
\hline Estrutura de Custo & $\mathrm{Sim}$ & $\mathrm{Não}$ & $\mathrm{Não}$ & $\mathrm{Sim}$ & Paridade competitiva \\
\hline $\begin{array}{c}\text { Laboratórios e } \\
\text { Equipamentos }\end{array}$ & $\mathrm{Sim}$ & $\mathrm{Sim}$ & $\mathrm{Sim}$ & $\mathrm{Sim}$ & $\begin{array}{c}\text { Vantagem } \\
\text { competitiva }\end{array}$ \\
\hline $\begin{array}{c}\text { Cultura e } \\
\text { Engajamento }\end{array}$ & $\mathrm{Sim}$ & $\mathrm{Sim}$ & $\mathrm{Sim}$ & $\mathrm{Sim}$ & $\begin{array}{c}\text { Vantagem } \\
\text { competitiva }\end{array}$ \\
\hline $\begin{array}{c}\text { Flexibilidade de } \\
\text { escopo }\end{array}$ & $\mathrm{Sim}$ & $\mathrm{Não}$ & $\mathrm{Não}$ & $\mathrm{Sim}$ & Paridade competitiva \\
\hline $\begin{array}{c}\text { Universidade } \\
\text { (Reputação) }\end{array}$ & $\mathrm{Sim}$ & $\mathrm{Sim}$ & $\mathrm{Sim}$ & $\mathrm{Sim}$ & $\begin{array}{c}\text { Vantagem } \\
\text { competitiva }\end{array}$ \\
\hline $\begin{array}{c}\text { Universidade } \\
\text { (Relacionamentos) }\end{array}$ & $\mathrm{Sim}$ & $\mathrm{Sim}$ & $\mathrm{Sim}$ & $\mathrm{Sim}$ & $\begin{array}{c}\text { Vantagem } \\
\text { competitiva }\end{array}$ \\
\hline
\end{tabular}

Fonte: Elaboração própria a partir de dados da pesquisa.

Ao aplicar o modelo VRIO aos recursos identificados como estratégicos para as EJs da UnB, percebe-se que "Estrutura de custo" e "Flexibilidade de escopo" não representam fontes de vantagem competitiva, porquanto estas têm sido alguma das estratégias mais comuns adotadas por empresas de qualquer setor. Por outro lado, os recursos que representam vantagem competitiva entre EJs são: Laboratórios e Equipamentos; Cultura e Engajamento; Universidade (Reputação e Relacionamento). Em comparação com os demais estudos referenciados neste trabalho, a quantidade de recursos aqui identificados como competitivos, aparenta ser, proporcionalmente, maior. Uma vez que os demais trabalhos foram realizados em mercados e empresas mais complexas e robustas, mas mesmo assim, levantaram quantidade semelhante de recursos competitivos ao que esta pesquisa levantou.

\section{$5 \quad$ Conclusĩes e Recomendações}

O presente trabalho teve como objetivo identificar os recursos competitivos empregados por empresas juniores. A metodologia de pesquisa e análise aplicada possibilitou a 
identificação de recursos estratégicos e competitivos dentre as EJs, no âmbito da UnB. O levantamento dos recursos foi feito de acordo com o modelo VRIO (Barney \& Hesterly, 2007).

Os principais recursos identificados foram:

i. $\quad$ Financeiros: "Estrutura de Custos" - custos, preços e isenção de impostos - não gera vantagem competitiva para as EJs, por não atenderem aos quesitos de raridade e imitabilidade. Entretanto, conclui-se que estes são recursos essenciais para a sobrevivência dessas empresas juniores, por possibilitarem seu posicionamento estratégico no mercado, ao alocarem esforços e investimentos em recursos que são competitivos;

ii. Físicos: "Laboratórios e Equipamentos" - espaço físico, materiais e equipamentos - disponibilizados pela Universidade são de suma importância para as EJs, podendo gerar vantagem competitiva. Por ser um polo acadêmico, responsável por pesquisas e avanços tecnológicos, a Universidade investe em equipamentos raros no mercado e a EJ pode se beneficiar disso;

iii. Individuais: "Flexibilidade de Escopo" não foi classificado como competitivo. Todavia, percebe-se ser este um recurso estratégico para as EJs no sentido da paridade competitiva. É um recurso que tende a elevar os níveis de satisfação dos clientes e a possibilidade de novas contratações por meio de indicações;

iv. Organizacionais: "Cultura e Engajamento" e "Universidade (Reputação e Relacionamento). Nota-se a relevância de recursos intangíveis no mercado de EJs, assim como concluído em trabalhos realizados em outros mercados e já citados anteriormente. A priori, percebeu-se que as culturas organizacionais de cada EJ apresentam particularidades, mas o perfil dos seus participantes lhes confere um diferencial competitivo. Ademais, o fato das EJs pertencerem a uma IES reconhecida, e nela serem criados relacionamentos valiosos, possibilita a geração de vantagem competitiva.

Como contribuições gerenciais, destaca-se que a aplicação do modelo VRIO à realidade das empresas juniores potencializa a identificação de recursos estratégicos que favoreçam a sua melhor competitividade. Assim sugere-se que as IES busquem: a) apoiar os discentes por meio da oferta de estruturas físicas que oportunizem o desenvolvimento das atividades relacionadas ao seu curso de formação; b) estimular uma cultura empreendedora que favoreça o maior envolvimento dos acadêmicos no movimento empresa júnior; c) reservar aos docentes carga horária suficiente para que estes possam se envolver nas orientações dos alunos, uma vez que parte do conhecimento e relacionamentos necessários ao desenvolvimento das atividades, advêm dos professores; d) aproximar EJs do mercado, por meio da construção de estratégicas de prospecção que lancem mão dos recurso reputacional presente na IES.

Este trabalho apresenta algumas limitações, as quais são seqüenciadas pelas sugestões de estudos futuros, quais sejam: limitou-se geograficamente às EJs do Distrito Federal, focando apenas na UnB. Desse modo, sugere-se a inclusão de outras EJs e IES que possibilitem analisar outras realidades e desenvolver estudos comparativos; o presente trabalho fixou sua análise de recursos e vantagens competitivas entre EJs. Apesar das suas diferenças e particularidades, o estudo da relação competitiva destas com empresas comuns de mercado continua com lacunas e pode ampliar as teses aqui citadas. Posto que os resultados 
apresentados neste trabalho foram baseados apenas na visão de agentes do âmbito estratégico das EJs, sugere-se a extensão do instrumento de pesquisa utilizado, para que se possa averiguar, também, as opiniões presentes nos níveis tático e operacional das empresas juniores.

\section{Referências}

Alves, C.A., Pizzinato, N.K., \& Gonçalves, M.N. (2010). A importância estratégica dos relacionamentos de negócios em redes de empresas: uma visão baseada no RBV - Resource Based View. REMark - Revista Brasileira de Marketing, São Paulo, 9(2), 166-189, mai./ago. Aragão, L.A., Forte, S.H.A.C., \& Oliveira, O.V. (2010). Visão baseada em recursos e capacidades dinâmicas no contexto brasileiro: a produção e a evolução acadêmica em dez anos de contribuições. REAd. Revista Eletrônica de Administração, 16(2), 127-150.

Balestrin, A., \& Vargas, L.M. (2004). A dimensão estratégica das redes horizontais de PMEs: teorizações e evidências. Revista de Administração Contemporânea, 8, 203-227.

Bardin, L. (1977). Análise de Conteúdo. Lisboa: Edições 70.

Barney, J.B. (1991). Firm Resources and Sustained Competitive Advantage. Journal of Management, 17, 99-120.

Barney, J.B. (2001). Resource-Based Theories of Competitive Advantage: a ten-year retrospective on the resource-based view. Journal of Management, 27(6), 643-650.

Barney, J.B., \& Hesterly, W.S. (2007). Administração Estratégica e Vantagem Competitiva. São Paulo: Pearson Prentice Hall.

Bezerra, E.D., \& Silva, D.E.P. (2013). Adoção de inovações em serviços turísticos: Um estudo de múltiplos casos em bares e restaurantes da orla de Aracaju (SE, Brasil). Revista Brasileira de Pesquisa em Turismo. São Paulo, 7(1), 14-34, jan./abr.

Brasil (2016). Lei $\mathrm{N}^{\mathrm{o}}$ 13.267, de 6 de abril de 2016. Disciplina a criação e a organização das associações denominadas empresas juniores, com funcionamento perante instituições de ensino superior. Recuperado em 04 novembro, 2019, de http://www.planalto.gov.br/ccivil_03/_ato2015-2018/2016/lei/L13267.htm.

Brasil Júnior (2018). Movimento Brasil Júnior. Recuperado em 04 novembro, 2019 em: htttp://www.brasiljunior.org.br.

Brito, L.A.L., \& Vasconcelos, F.C. (2004). A heterogeneidade do desempenho, suas causas e o conceito de vantagem competitiva: proposta de uma métrica. Revista de Administração Contemporânea, 8, 107-129.

Feitosa, M.A.J.S., \& Firmo, L.A. (2013). Bases do Comprometimento Organizacional: um estudo comparativo em empresas juniores. Gestão e Sociedade, Belo Horizonte, 7(16), 51-69.

Flick, U. (2009). Introdução à pesquisa qualitativa. 3. ed. Porto Alegre: Artmed. 405p.

Fonseca, M.R., \& Cunha, M.A. (2015). Desenvolvimento de vantagem competitiva sob a ótica da Visão Baseada em recursos. Caderno Profissional de Administração - UNIMEP, 5(1).

Fontanella, B.J.B., Ricas, J., \& Turato, E.R. (2008). Amostragem por saturação em pesquisas qualitativas em saúde: Contribuições teóricas. Cad. Saúde Pública, Rio de Janeiro, 24(1), $17-$ 27 , jan. 
Gohr, C.F., Santos, L.C., Burin, C.B., Marques, M.D.S., \& Arai, R.M. (2011). Recursos estratégicos e vantagem competitiva: aplicação do Modelo VRIO em uma organização do setor sucroalcooleiro. Revista Gestão Organizacional, 4(1), 115-139.

Hermes, L.C.R., Cruz, C.M.L., \& Santini, L. (2016). Vantagens Competitivas do Mix de Varejo sob a Ótica da VRIO: um Estudo de Caso em um Supermercado Independente. Revista Brasileira de Marketing, 15(3), 373-389.

Hexsel, A.E., De Toni, D., Wilk, E.O., \& Larentis, F. (2008) Visão da Firma Baseada em Recursos e Reconfiguração da Cadeia de Valor: O Caso da Vitivinícola Cordilheira de Santana. XXV Simpósio de Gestão e Inovação Tecnológica. ANPAD. Brasília, DF.

Hoffmann, V.E., Vieira, D.P., Reyes Jr., E., \& Melo, M.S.R. (2015). Estrategia Empresarial en Períodos de Crisis: Un estudio del sector hotelero de la región metropolitana de Belo Horizonte - Brasil. Estudios y Perspectivas en Turismo, 24, 681-700.

Hoskisson, R.E. (2000). Strategy in emerging economies. Academy of Management Journal, 43(3), 249-267.

Jaafar, M., \& Abdul-Aziz, A. (2005) Resource-Based View and Critical Success Factors: A Study on Small and Medium Sized Contracting Enterprises (SMCEs) in Malaysia. International Journal of Construction Management, 5(2), 61-77.

Jarillo, J.C. (1988). On Strategic Networks. Strategic Management Journal. 9, 31-41.

Lee, G., \& Lin, H. (2005). Customer perceptions of e-service quality in online shopping. International Journal of Retail \& Distribution management. 33(2), 161-176.

Oliveira, O.V., \& Forte, S.H.A.C. (2011). Identificação dos recursos competitivos de utilização mais provável pela indústria bancária brasileira de 2008 a 2012. Revista de Administração, 46(3), 243-257.

Pavão, Y.M.P., Sehnem, S., \& Hoffmann, V.E. (2011). Análise dos recursos organizacionais que sustentam a vantagem competitiva. Revista de Administração, São Paulo, 46(3), 228242.

Penrose, E.T. (1959). The theory of the growth of the firm. New York: Wiley.

Peteraf, M. (1993). The Cornestones of Competitive Advantage: A Resource-based View. Strategic Management Journal, 14(3), 179-191.

Porter, M. (1986). Estratégia competitiva. Campus, São Paulo.

Porter, M. (1991). Competição: Estratégias Competitivas Essenciais. Rio de Janeiro: Campus, 167-208.

Rijnsoever, F.J.v., Hessels, L.K., \& Vandeberg, R.L.J. (2008). A resource-based view on the interactions of university researchers. Research Policy, 37, 1255-1266.

Rodrigues, C.M.C., Vieira, K.M., Ribas, F.T.T., Arruda, G.S., \& Catarina, G.M.F.S. (2010). Relação entre os valores pessoais e comprometimento organizacional: o caso das empresas juniores de Santa Maria. Revista Eletrônica Gestão de Gestão Organizacional, 8(2), 245-64, maio-ago.

Sanches, P.L.B., \& Machado, A.G.C. (2013). Estratégias de Inovação e RBV: Evidências em uma Empresa de Base Tecnológica. Revista de Administração e Inovação, São Paulo, 10(4), 183-207, out./dez.

Selznick, P. (1957). Leadership in Administration: A Sociological Perspective. New York: Harper e Row. 
Silva, D.L.B., Almeida, G.M.P, \& Ferreira, L.B. (2015). Desenvolvimento de Competências em Empresas Juniores: a experiência dos líderes nas EJs da Universidade Federal do Maranhão (UFMA). Anais do XII Seminário ANPTUR, 1-15.

Silva, T.N., Dias, M.F.P., Santos, S., Rosa, N.P., \& Mendonça, E.S. (2011). Priorização de critérios competitivos das operações baseado nos recursos estratégicos. Contextus - Revista Contemporânea de Economia e Gestão, 9(1), 7-17.

Thorelli, H.B. (1986). Networks: Between Markets and Hierarchies. Strategic Management Journal. 7(1), 37-51.

Vergara, S.C. (1997). Projetos e relatórios de pesquisa em Administração. 9. ed. São Paulo: Atlas.

Verschoore, J.R., Balestrin, A., \& Perucia, A. (2014). Small-Firm Networks: hybrid arrangement or organizational form? O\&S - Salvador, 21(69), 275-292 - abril/junho.

The Higher Education [THE]. (2019). World University Ranking. Recuperado em 04 novembro, 2019, de https://www.timeshighereducation.com/content/world-universityrankings. 